\title{
The value of diagnostic tests for reassurance
}

Hiske van Ravesteijn ${ }^{1,2}$, Peter Lucassen ${ }^{1}$, Tim olde Hartman ${ }^{1}$

1 Department of primary and community care, Radboud University Nijmegen Medical Centre, the Netherlands

2 Department of psychiatry, Radboud University Nijmegen Medical Centre, the Netherlands

\section{Reassuring the patient}

Reassurance is «the action of removing someone's doubts or fears», according to the Oxford Dictionary of English. Providing reassurance is one of the most important tasks of GPs. Patients

often fear that something serious is wrong and expect to be reassured by their physician. Physicians can make use of their communication skills to make the fears of the patient explicit. They can also make use of diagnostic tests to reassure the patient. The use of diagnostic tests for reassurance of the patient is considerable in family practice. In a Dutch cohort study in primary care $(n=31,000)$ the reasons for requesting diagnostic tests were recorded over a one year period. Of all requested diagnostic tests, reassurance of the patient was the fourth reason for ordering tests, in $11 \%$ of the requests it was the main reason for testing [1].

But, is doing additional testing effective? Does it really reassure patients? And what are the adverse effects? For example, McDonald et al. examined in a non-randomized trial whether normal test results reduce the patients' fears [2]. Patients were referred for echocardiography, because of symptoms $(n=10)$, or because of a heart murmur $(n=30)$. All but one had normal test results. The patients presenting with symptoms were all left with worries despite a normal test result. Of the 30 patients with a heart murmur, 20 became anxious after being told about the detection of the murmur; after receiving the normal test result 11 still had residual worries. Therefore, the question still remains: do negative test results reassure patients?

\section{Evidence for reassurance through diagnostic tests}

To assess the effectiveness of diagnostic tests in providing reassurance to patients, we performed a systematic review of randomized controlled trials [3]. RCT's were included examining the value of various diagnostic tests, both in primary care and outpatient secondary care settings. The levels of reassurance of patients receiving the results of the diagnostic test, were compared to those of a control 
group who did not receive tests or who were not given test results. We performed a narrative synthesis of the retrieved evidence.

We have only found 5 RCTs with 1,544 participants about this subject. These included studies were published between 1981 and 2009. The researchers of these studies measured the reassuring effect of:

- Electrocardiography and blood tests for chest pain [4];

- Radiography of the lumbar spine for low back pain [5-7];

- Magnetic resonance imaging for low back pain [8];

- Magnetic resonance imaging for headache [9]

- Blood tests for five specified un-explained conditions [10].

All trials were conducted in the USA or Europe. The primary outcome measure was the level of reassurance, as measured with various scales. Three trials defined reassurance as "taking away the concern that something serious is wrong" and two trials as "absence of anxiety". Reported follow-up ranged from four months to one year.

The overall quality of the studies was low due to high drop-out rates (16\% to $77 \%$ ). Strikingly, none of the studies found a significant difference in reassurance levels between intervention and control groups at the end of follow-up; one study found an interim benefit at three months which disappeared at one year follow-up [9].

In conclusion, there was a lack of methodologically sound studies assessing the reassuring value of diagnostic tests. More trials are needed to assess the efficacy of specific diagnostic tests in providing reassurance. The available results indicate that there is no evidence for the use of diagnostic tests for the mere goal of reassuring the patient.

\section{Providing effective reassurance is a process, not an event}

Besides using diagnostic tests, physicians have several other strategies for reassuring their patients, for example: by paying sincere attention by listening well, explaining medical terminology in comprehensible language and 'laying hands' during physical examination [11]. However, especially in patients with high health anxiety, reassuring the patient is not an easy task. It is important to keep an open dialogue with these patients. What is the patient afraid for? Does the patient know why he/she is afraid for that particular disease? It is relevant to ask whether the patient expects a diagnostic test, and if so, to ask what the patient expects from the outcome. Both the possibility of a positive test result and a negative test result should be discussed with the patient. In the end, the physician will have to decide, together with the patient, whether the expected reassuring effect of a negative test result outweighs the risk for a false-positive (or false-negative) result. Once the test has been performed this should not be the end of the dialogue. We recommend discussing the results face-to-face in order to keep up the conversation with the patient about his/her anxiety level. Did the test results provide the patient with the expected level of reassurance? If not, the physician might suggest choosing another solution for future health related worries. In addition, in patients with recurrent episodes of high health anxiety Cognitive Behavioural Therapy (CBT)[12] or Mindfulness-Based Cognitive Therapy (MBCT)[13] might be considered, as these therapies have been shown to be effective in these patients. These therapies might provide patients with new insights in their thought patterns and reassurance seeking behavior [14].

\section{Conclusion}

To conclude, regarding the current evidence from RCT's, diagnostic test results seem to make very little contribution to the level of reassurance of patients. A clear explanation and watchful waiting can make 
additional diagnostic testing unnecessary. If the health anxiety of the patient remains high, diagnostic tests can be used for the specific aim of reassurance, provided that the physician combines the use of the test with adequate guidance. It is quintessential to keep an open dialogue with the patient, before and after testing. In future studies about the value of diagnostic tests, a distinction should be made between the reassurance of patients in general and the reassurance of patients who have expressed a specific fear during the consultation.

\section{References}

1. Van Boven K, Dijksterhuis P, Lamberts H. Defensive testing in Dutch family practice. Is the grass greener on the other side of the ocean? The Journal of family practice 1997; 44: 468-72

2. McDonald IG, Daly J, Jelinek VM, et al. Opening Pandora's box: the unpredictability of reassurance by a normal test result. BMJ 1996; 313: 329-32; http://dx.doi.org/10.1136/bmj.313.7053.329

3. van Ravesteijn $H$, van Dijk I, Darmon D, et al. The reassuring value of diagnostic tests: a systematic review. Patient Educ Couns 2012; 86: 3-8; http://dx.doi.org/10.1016/j.pec.2011.02.003

4. Sox HC, Jr. Probability theory in the use of diagnostic tests. An introduction to critical study of the literature. Ann Intern Med 1986; 104: 60-6; http://dx.doi.org/10.7326/0003-4819-104-1-60

5. Kendrick D, Fielding K, Bentley E, et al. The role of radiography in primary care patients with low back pain of at least 6 weeks duration: a randomised (unblinded) controlled trial. Health Technol Assess 2001; 5: 1-69

6. Kendrick D, Fielding K, Bentley E, et al. Radiography of the lumbar spine in primary care patients with low back pain: randomised controlled trial. BMJ 2001; 322: 400-5; http://dx.doi.org/10.1136/ bmj.322.7283.400

7. Miller P, Kendrick D, Bentley E, et al. Cost-effectiveness of lumbar spine radiography in primary care patients with low back pain. Spine (Phila Pa 1976) 2002; 27: 2291-7; http://dx.doi. org/10.1097/00007632-200210150-00021

8. Ash LM, Modic MT, Obuchowski NA, et al. Effects of diagnostic information, per se, on patient outcomes in acute radiculopathy and low back pain. AJNR American journal of neuroradiology 2008; 29: 1098-103; http://dx.doi.org/10.3174/ajnr.A0999

9. Howard L, Wessely S, Leese M, et al. Are investigations anxiolytic or anxiogenic? A randomised controlled trial of neuroimaging to provide reassurance in chronic daily headache. J Neurol Neurosurg Psychiatry 2005; 76: 1558-64; http://dx.doi.org/10.1136/jnnp.2004.057851

10. van Bokhoven MA, Koch $\mathrm{H}$, van der Weijden $\mathrm{T}$, et al. Influence of watchful waiting on satisfaction and anxiety among patients seeking care for unexplained complaints. Ann Fam Med 2009; 7: 11220; http://dx.doi.org/10.1370/afm.958

11. Koch H, van Bokhoven MA, ter Riet G, et al. Demographic characteristics and quality of life of patients with unexplained complaints: a descriptive study in general practice. Qual Life Res 2007; 16: 1483-9; http://dx.doi.org/10.1007/s11136-007-9252-y

12. Thomson AB, Page LA. Psychotherapies for hypochondriasis. Cochrane database of systematic reviews 2007: CD006520

13. McManus F, Surawy C, Muse K, et al. A randomized clinical trial of mindfulness-based cognitive therapy versus unrestricted services for health anxiety (hypochondriasis). J Consult Clin Psychol 2012; 80: 817-28; http://dx.doi.org/10.1037/a0028782

14. Williams MJ, McManus F, Muse K, et al. Mindfulness-based cognitive therapy for severe health anxiety (hypochondriasis): an interpretative phenomenological analysis of patients' experiences. Br J Clin Psychol 2011; 50: 379-97; http://dx.doi.org/10.1111/j.2044-8260.2010.02000.x 